\title{
The community of equinoideos (echinoidea: echinodermata) of the tuxpan reef and its relationship with the attributes of the substrate
}

Volume 6 Issue 3 - 2017

\section{Opinion}

The community of Equinoideos that is influenced by structural and environmental factors, contributes to the balance in the coral reefs since it regulates the biomass of algae, the main competitor of the corals. In the present work, the structure of the urchin community in the Tuxpan reef (north location of the reef corridor of the southwestern Gulf of Mexico) was evaluated. The organisms are associated with their community attributes: depth, zoning and characteristics of the substrate. The study was doing at the ridge and reef slopes, in which the following strata were considered: $3-5,5-10,10-15 ; 15-20,20-$ 25 and $25-30 \mathrm{~m}$. On each stratum, there were evaluated the richness and abundance of Equinoideos and the type of substrate, coral cover, benthic groups and structural complexity. For the evaluation of benthos, phototransects were made and analyzed using the Coral Point Count program. Richness and abundance as well as ecological indexes (Simpson, Shannon-Wiener and Equity) were estimated at the different scales (reef, zones and environments) with richness and abundance data. Comparisons of richness and abundance between zones and environments were performed using one-way parametric and nonparametric ANOVAs. The attributes of the substrate were related to the community aspects by means of canonical correspondence analysis (CCA). Echinometra lucunter and Echinometra viridis, representing $47.4 \%$ and $44 \%$ of the total species found in the Tuxpan reef community. At scale of zones the wealth is similar, but greater in the reef plain (seven species). The average abundance was higher in the leeward crest and lower in the areas of seagrass. In the slopes, both wealth and abundance, in general, descend as depth increases and this influence the values of dominance and equity indices. The crests have low values of equity and high dominance compared to the environment of seagrass where a greater equity was determined. The substrate of the Tuxpan reef is represented by ten categories: of these, corals showed the greatest coverage $(28 \%)$ and octocorals, zooantides and sponges accounted for only $3 \%$ of the total. Dominant benthic groups as well as structural complexity vary depending on areas and reef environments. In the leeward slope, an increase was observed in the rock with macroalgae and a decrease of the coral cover as the depth increases. The CCA analysis for the plain shows an association of Lytechinus variegatus and Tripneustes ventricosus with marine grass; Diadema antillarum with coral remains; Echinometra viridis with rock covered with macroalgae and Echinometra

\author{
Salas P rez JJ, Gonzalez Gandara C, Jord n \\ Garza G \\ Facultad de Ciencias Biologicas y Agropecuarias, Universidad \\ Veracruzana, México
}

\begin{abstract}
Correspondence: Salas-Pérez JJ, Facultad de Ciencias Biologicas y Agropecuarias, Universidad Veracruzana, México, Email jsalasp39@yahoo.es
\end{abstract}

Received: September 21, 2017 | Published: September 25, 2017

lucunter, Arbacia punctulata and Eucidaris tribuloides associated with coral rock. In the leeward slope, it was associated to: E. tribuloides, and $D$. antillarum with areas of 15 to $20 \mathrm{~m}$ deep and with the substrate: rock with macroalgae. On the other hand, A. punctulata and $T$. ventricosus were associated with the coral rock and the layers from 5 to $10 \mathrm{~m}$ deep. The presence of Lytechinus williamsi, is related to coral rock and depths of 3 to 5 and 10 to $15 \mathrm{~m}$; Finally, E. lucunter is associated with rock substrate with macroalgae, but it does not show any relation to depth. In the windward slope associations of $E$. lucunter were defined with areas from 3 to $5 \mathrm{~m}$ deep; $E$. viridis and $L$. williamsi with rock with crusted algae and sponges as well as depths of 10 to $20 \mathrm{~m}$; D. antillarum was associated to the rocky substrate and depths of 5 to 10 and 20 to $25 \mathrm{~m}$. Finally, E. tribuloides and $A$. punctulata were associated with rock with filamentous algae and coral remains as well as depths of 3 to 5 and 25 to $30 \mathrm{~m}$ respectively. The Tuxpan reef hedgehog community shows a relationship of substrate attributes, depth and geomorphology with the richness and abundance of the community.

\section{Acknowledgments}

None.

\section{Conflicts of interest}

None. 